\title{
VIBRATION ANALYSIS OF A TIRE IN GROUND CONTACT UNDER VARIED CONDITIONS
}

\author{
Murat Karakus $^{1}$, Aydin Cavus ${ }^{1}$, Mehmet Colakoglu ${ }^{2 *}$ \\ ${ }^{1}$ Afyon Kocatepe University, Faculty of Technology, ANS Campus, 03200 \\ Afyonkarahisar, Turkey \\ ${ }^{2}$ Department of Mechanical and Aeronautical Engineering, University of \\ Pretoria, Pretoria, 0002, South Africa
}

[Received 05 December 2016. Accepted 20 March 2017]

\begin{abstract}
The effect of three different factors, which are inflation pressure, vertical load and coefficient of friction on the natural frequencies of a tire (175/70 R13) has been studied. A three dimensional tire model is constructed, using four different material properties and parts in the tire. Mechanical properties of the composite parts are evaluated. After investigating the free vibration, contact analysis is carried out. A concrete block and the tire are modelled together, using three different coefficients of friction. Experiments are run under certain conditions to check the accuracy of the numerical model. The natural frequencies are measured to describe free vibration and vibration of the tire contacted by ground, using a damping monitoring method. It is seen, that experimental and numerical results are in good agreement. On the other hand, investigating the impact of three different factors together is quite difficult on the natural frequencies. When some of these factors are assumed to be constant and the variables are taken one by one, it is easier to assess the effects.
\end{abstract}

KEY WORDS: Automobile tire, vibration, vertical load, inflation pressure, coefficient of friction.

\section{INTRODUCTION}

Tire providing the contact between vehicle and road is an important power transmission and energy absorption components in vehicles. Therefore, researchers on tire performance have been paying more attention to optimum design, from different viewpoints, in the automobile and airplane industries. Some studies have been carried out for the tire analysis with regard to their vibration properties. For example, free vibration of a radial pneumatic tire [1], P195/60R14, is analyzed by Jia et al. [2], using Rayleigh-Ritz method, and shell and solid finite element models (FEM). Effects of ply-angles of steel belts and inflation pressure of the tire to natural frequencies are also studied. The most accurate one is solid FEM, but it has the longest

\footnotetext{
${ }^{*}$ Corresponding author e-mail: mehmetcolakoglu@ Ymail.com
} 
calculation time. The relative error is between $20-30 \%$ for the first natural frequency, when the results are compared by experiments, but it goes down to $1.4 \%$ for the fifth natural frequency. The free and forced vibrations of the tire is determined by Waki et al. [3], using wave finite element method. The FEM of a short section of the tire is formed, using the commercial package Ansys. It is concluded, that the wave FEM is a powerful tool to investigate the dynamic behaviour of a complex structure with small calculation cost. At the same time, the results are in good agreement with experimental data.

Although, the free vibration analysis of the tire providing the contact between the vehicle and road is essential, its vibration properties must also be investigated in working condition. An analytical method, which allows to obtain the natural frequencies, is presented for the tire in ground contact by Soedel and Prasad [4]. Kozhevnikov [5] develops a mathematical model for a free and a loaded tire. It is assumed, that the wheel with the reinforced tire consists of a disc, which is an absolutely rigid body, having six degrees of freedom, joined to the side wall of the tire, represented in the un-deformed state. The contact area rectangle is taken as constant in the calculation. It is advised, that the results of the analysis could be used to estimate the level of noise, which occurs when a vehicle moves on an uneven surface. Another mathematical model is developed to investigate the natural frequencies and modes of rolling tires in ground contact by Huang [6], but in this model, an elastic foundation ring is adopted for the tire. The natural frequency and damping ratio in the tire-wheel system are measured by Kim et al. [7], not only for different tires, but also at different boundary conditions. Indoor experiments are carried out and designed as real environmental conditions. In addition, results are compared with the yield experimental results from using the automobile under real conditions. From these results, the validity of the indoor tests could be verified. The vibration characteristics of the radial tire are studied numerically and experimentally by Guan et al [8]. It is considered, that mode shapes of the radial vibration are in a strong regularity with the change of the mode order.

Geng et al. [9] deals with a research approach specifically designed for the measurement, identification and modelling of damping in pneumatic tires. A non-contact vibration measurement technique, using laser with linearity, simplicity, reliability and low cost to investigate rotating imbalance for quality testing of solid tires is proposed by Chetpattananondh et al. [10] with an explanation of experimental results. Some other studies are also carried out, using different parameters to investigate the vibration of the tire. The effect of rotation on the tire dynamics and vibration on the deformed rolling tire are modelled by Kim and Bolton [11] and Lopez et al. [12], respectively. Formulas for tire contact characteristics are obtained by Li et al [13] and the calculation formula of lateral stiffness of tread element is determined, using 
the energy method. The lateral self-excited vibration occurs under the certain conditions. Vehicle speed, vertical load and tire pressure have great influence on the vibration characteristics. In addition, the rolling tire dynamics is simulated [14] and used to detect bead area damage [15]. The vibration of the automobile tire due to tire-road excitation [16], road roughness [17], and bump impact [18] is analyzed in three different studies.

The contact between the tire and the ground depends on many parameters, such as the coefficient of friction, lateral force applied to the tire, vertical load, structure of the tire, the crown depth and the inflation pressure. The aim of this study is investigating the effects of some of these parameters on the vibration of a passenger car tire, experimentally and numerically. The inflation pressure and the rotational speed are the parameters in the free vibration analysis. On the other hand, the coefficient of friction, which was not considered previously, the inflation pressure, and the vertical load together are chosen as the effective factors in the vibration of the tire having ground contact. First, the tire having dimension of 175/70 R13 is modelled numerically in three dimensions (3D), using Ansys software. Then, the contact analysis is carried out. A concrete block and a tire are modelled together. The natural frequencies are investigated for free vibration of the tire and for the tire, which is contacted by ground. It is observed that the relationships among three parameters together are not the same on the first six natural frequencies, which react them separately, especially for the coefficient of friction. As a result, the inflation pressure is the most effective factor in the tire, contacted by ground.

\section{EXPERIMENTAL METHOD}

175/70 R13 B250 82T radial tire, which has maximum vertical load capacity of 4660 $\mathrm{N}$ (475 kg), is used in the experiment. Using a damping monitoring method [19], natural frequencies are measured to describe the free vibration and the vibration of the tire in ground contact. First, the tire is hung from the rim by a hook and rope to perform free vibration tests. The accelerometer is located at an appropriate place and then vibration is induced in the tire using a small steel hammer. The accelerometer (PCB 336C) measures the vibration and produces an electrical signal, which is amplified by the charge amplifier (PCB 482 B11) and finally, input to the computer, using a Gravis ultrasound card for data acquisition is generated. A Fast Fourier Transform (FFT) is performed for measurement of the natural vibration modes by the software. There are two different programs in this damping monitoring device: the first one controls hardware and the second one is used to obtain frequency response from the time response using the FFT. The measurements are carried out using three different inflation pressures which are $159 \mathrm{kPa}(23 \mathrm{psi}), 200 \mathrm{kPa}(29 \mathrm{psi})$, and $241 \mathrm{kPa}(35 \mathrm{psi})$ to describe the effect of the inflation pressure in the natural frequencies. 
In the second experiment, the tire is attached to the front shaft of the car and is applied load, which is the self weight of the car on the tire is measured using a load cell, located under the tire. Again, the natural frequencies are measured for three different inflation pressures under the constant load of $1215 \mathrm{~N}$ in the front tire. Later, experimental results are compared with numerical results to check the accuracy of the numerical analysis.

\section{NUMERICAL MODEL AND METHOD}

The dimensions and maximum load capacity of the radial tire (175/70 R13 B250 $82 \mathrm{~T}$ ), which is used in this study, is taken from a commercially available tire and it is modelled, using Ansys program in two dimensions (2D), as shown in Fig. 1. There are four different parts in this composite tire model: treads, sidewall, bead bundle, and main composite body. At the same time, 2D model in Fig. 1 is rotated in $360^{\circ}$ about the rim diameter to get 3D tire model.

Determining material properties of the tire is one of the most difficult and crucial parts to perform accurate analysis. The tire is first cut to calculate the material properties for each part. All dimensions are taken from the tire to determine volume fraction of the materials for each part. The tread part in the tire is manufactured only from polymer rubber and it is assumed, that it is an isotropic material. On the other hand, the sidewall is manufactured, using two different materials, which are rubber and cord cloth. Therefore, this part has orthotropic composite material properties. The bead bundle of the tire also contains two different materials, which are steel belts and rubber. The main body consists of two layers of steel belts, which are placed

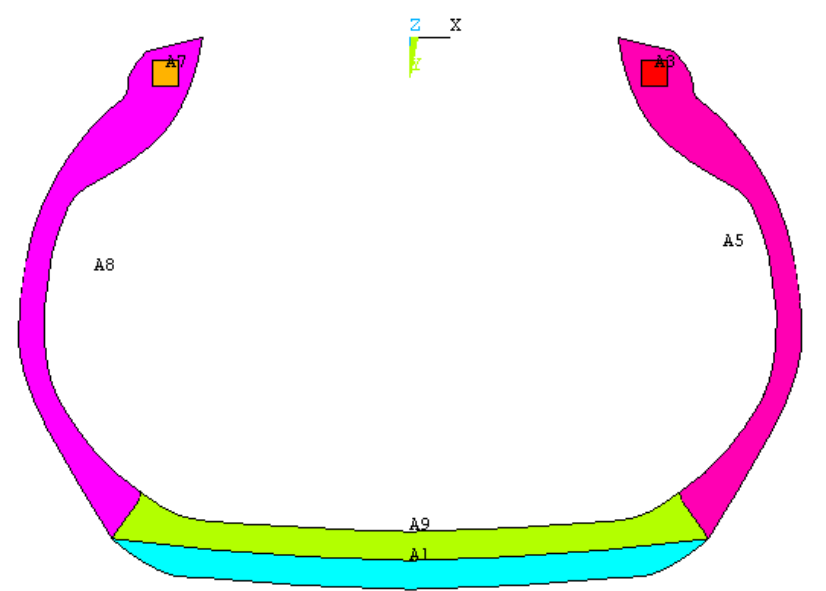

Fig. 1. 175/70 R13 tire model in 2D. 
with $\pm 20^{\circ}$ angles, two layers of cord clothes, and rubber. Its material properties are also calculated as an orthotropic composite material, like it is performed for the bead bundle and the side wall. The material properties of the polymer cord cloth for a single layer are based on the mosaic model, developed for plain weave composites [20]. This model gives the homogenized material properties, considering the properties of the fibers, the matrix, and their contributions [21]. The material properties of the parts, the tread, the sidewall, the bead bundle, and the main composite body are presented in Table 1.

Table 1. Material properties of the parts for $175 / 70$ R13 tire

\begin{tabular}{|l|l|l|l|l|}
\hline \hline $\begin{array}{l}\text { Tire } \\
\text { parts }\end{array}$ & $\begin{array}{c}\text { Material } \\
\text { type }\end{array}$ & $\begin{array}{c}\text { Elastic modulus } \\
E(\mathrm{MPa})\end{array}$ & $\begin{array}{c}\text { Poisson ratio } \\
\nu\end{array}$ & $\begin{array}{c}\text { Shear modulus } \\
G(\mathrm{MPa})\end{array}$ \\
\hline \multirow{4}{*}{ Tread } & & $E_{x}=14$ & & \\
& isotropic & $E_{y}=14$ & $\nu=0.45$ & $G=5$ \\
& & $E_{z}=14$ & & \\
\hline \multirow{5}{*}{ Sidewall } & \multirow{2}{*}{ orthotropic } & $E_{x}=14.7$ & $\nu_{x y}=0.049$ & $G_{x y}=5.3$ \\
& & $E_{y}=113$ & $\nu_{x z}=0.049$ & $G_{y z}=5.3$ \\
& & $E_{x}=113$ & $\nu_{y z}=0.057$ & $G_{x z}=5.3$ \\
\hline \multirow{5}{*}{ Main body } & \multirow{2}{*}{ orthotropic } & $E_{y}=170$ & $\nu_{x y}=0.044$ & $G_{x y}=6.2$ \\
& & $E_{z}=1844$ & $\nu_{x z}=0.13$ & $G_{y z}=364$ \\
& & $E_{x}=21.5$ & $\nu_{x y}=0.38$ & $G_{x z}=350$ \\
\hline \multirow{5}{*}{ Bead bundle } & orthotropic & $E_{y}=21.5$ & $\nu_{x z}=0.0012$ & $G_{y z}=5.3$ \\
& & $E_{z}=70000$ & $\nu_{y z}=0.0012$ & $G_{x z}=5.3$ \\
\hline
\end{tabular}

Ansys program first performs preliminary check, using equation (1) to examine the validity of the orthotropic material properties, which are entered into the program, whether they are appropriate. Otherwise, the program gives an error message.

$$
1-v_{x y}^{2} \frac{E_{y}}{E_{x}}-v_{y z}^{2} \frac{E_{z}}{E_{y}}-v_{x z}^{2} \frac{E_{z}}{E_{x}}-2 v_{x y} v_{y z} v_{x z} \frac{E_{z}}{E_{x}}>0 .
$$

Choosing the right element type to get accurate results is one of the important parts in analysis. From Ansys library, SOLID92, a commonly used element type for 3D analysis is chosen. SOLID92 has quadratic displacement behaviour and is well suited to model irregular meshes. Then, the tire which has four different parts is meshed using 10-node tetrahedral elements, having three degrees of freedom at each node: translations in the nodal $x, y$, and $z$ directions and consists of 21551 elements and 39181 nodes. Also, this element has plasticity, creep, swelling, stress stiffening, 


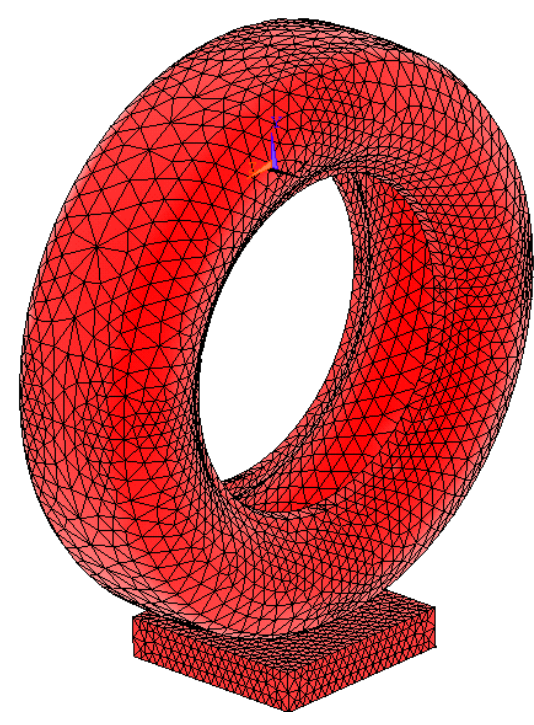

Fig. 2. Meshed tire in ground contact.

large deflection, and large strain capabilities. The free vibration analysis is carried out in this model, using Block Lanczos method.

The concrete block with a size of $200 \times 200 \times 40 \mathrm{~mm}^{3}$ is modelled to investigate vibration of the tire in ground contact. It is an isotropic material with an elastic modulus of $29 \mathrm{GPa}$ and Poison's ratio of 0.15 . The contact between the tire and the concrete block is described, using surface to surface contact elements CONTA174 and TARGE170 and shown in Fig. 2.

In numerical vibration analysis of the tire contacted by ground, three different inflation pressures and coefficients of friction between the tire and the concrete block are used, as shown in Table 2. In addition, four different vertical loads are applied to the tire to consider the relationship among them.

Table 2. Applied conditions to the numeric model, contacted by ground to determine natural frequencies

\begin{tabular}{|c|c|c|c|}
\hline \hline & Inflation pressure & Vertical load $(\mathrm{N})$ & Coefficient of friction \\
\hline 1 & $159 \mathrm{kPa}(23 \mathrm{psi})$ & 1000 & 0.1 \\
\hline 2 & $200 \mathrm{kPa}(29 \mathrm{psi})$ & 2000 & 0.4 \\
\hline 3 & $241 \mathrm{kPa}(35 \mathrm{psi})$ & 3000 & 0.8 \\
\hline 4 & & 4000 & \\
\hline
\end{tabular}




\section{RESUlTS AND DisCUSSION}

\subsection{FREE VIBRATION ANALYSIS OF THE TIRE}

Free natural frequencies are measured experimentally under three different inflation pressures. Modal analysis is also carried out using 3D numerical model after initial pre-stress analysis is performed for each inflation pressure. According to the results shown in Table 3, the natural frequencies increase with increased inflation pressure. Both experimental and numerical results are reasonable if the relevant of them are compared by the results of Kung [1], Jia et al. [2], and Kim et al. [7]. In addition,

Table 3. The natural frequencies of the free vibration of the tire (175/70 R13), under three different inflation pressures

\begin{tabular}{|c|c|c|c|c|c|c|}
\hline \hline $\begin{array}{c}\text { Inflation } \\
\text { pressures }\end{array}$ & \multicolumn{2}{|c|}{$159 \mathrm{kPa}(23 \mathrm{psi})$} & \multicolumn{2}{c|}{$200 \mathrm{kPa}(29 \mathrm{psi})$} & \multicolumn{2}{c|}{$241 \mathrm{kPa}(35 \mathrm{psi})$} \\
\hline $\begin{array}{c}\text { Natural } \\
\text { frequencies }\end{array}$ & $\begin{array}{c}\text { Numerical } \\
(\mathrm{Hz})\end{array}$ & $\begin{array}{c}\text { Experimental } \\
(\mathrm{Hz})\end{array}$ & $\begin{array}{c}\text { Numerical } \\
(\mathrm{Hz})\end{array}$ & $\begin{array}{c}\text { Experimental } \\
(\mathrm{Hz})\end{array}$ & $\begin{array}{c}\text { Numerical } \\
(\mathrm{Hz})\end{array}$ & $\begin{array}{c}\text { Experimental } \\
(\mathrm{Hz})\end{array}$ \\
\hline 1 & 123.82 & 113.9 & 135.28 & 121.92 & 145.53 & 125.97 \\
\hline 2 & 147.49 & 153.25 & 159.97 & 145.93 & 171.31 & 152.39 \\
\hline 3 & 155.32 & 164.03 & 168.12 & 176.26 & 179.78 & 167.74 \\
\hline 4 & 206.97 & 191.97 & 214.69 & 205.86 & 221.8 & 184.67 \\
\hline 5 & 215.08 & - & 222.9 & - & 230.24 & - \\
\hline
\end{tabular}

Table 4. The natural frequencies of the free vibration of the tire (175/70 R13) with different rotational speeds

\begin{tabular}{|c|c|c|c|c|c|c|c|c|c|}
\hline \hline $\begin{array}{c}\text { Inflation } \\
\text { pressures }\end{array}$ & \multicolumn{3}{|c|}{$159 \mathrm{kPa}$} & \multicolumn{3}{c|}{$200 \mathrm{kPa}$} & \multicolumn{3}{c|}{$241 \mathrm{kPa}$} \\
\hline $\begin{array}{c}\text { Rotational } \\
\text { speeds (rad/s) }\end{array}$ & 9.16 & 13.74 & 18.30 & 9.16 & 13.74 & 18.30 & 9.16 & 13.74 & 18.30 \\
\hline $\begin{array}{c}\text { Natural } \\
\text { frequencies }\end{array}$ & $\mathrm{Hz}$ & $\mathrm{Hz}$ & $\mathrm{Hz}$ & $\mathrm{Hz}$ & $\mathrm{Hz}$ & $\mathrm{Hz}$ & $\mathrm{Hz}$ & $\mathrm{Hz}$ & $\mathrm{Hz}$ \\
\hline 1 & 123.82 & 123.83 & 123.84 & 135.29 & 135.29 & 135.30 & 145.53 & 145.54 & 145.54 \\
\hline 2 & 147.49 & 147.51 & 147.53 & 159.98 & 159.99 & 160 & 171.31 & 171.32 & 171.34 \\
\hline 3 & 155.32 & 155.34 & 155.36 & 168.13 & 168.14 & 168.16 & 179.78 & 179.79 & 179.81 \\
\hline 4 & 206.97 & 206.98 & 206.98 & 214.69 & 214.69 & 214.69 & 221.8 & 221.8 & 221.81 \\
\hline 5 & 215.08 & 215.10 & 215.11 & 222.9 & 222.91 & 222.92 & 230.25 & 230.26 & 230.27 \\
\hline
\end{tabular}


the effect of rotational speed in the natural frequencies for free vibration is determined numerically, using three different angular velocities, $9.16 \mathrm{rad} / \mathrm{s}, 13.74 \mathrm{rad} / \mathrm{s}$, and $18.30 \mathrm{rad} / \mathrm{s}$. Nevertheless, this effect is very small and negligible, as shown in Table 4 .

\subsection{VibRATION ANALYSIS OF THE TIRE CONTACTED BY THE GROUND}

Experimental and numerical results are firstly compared to check accuracy of the numerical results. The experiments are carried out, using three different inflation pressures, under the self weight of the car, $1215 \mathrm{~N}$, as the vertical load in the front tires. Then, the numerical analysis is considered, after initial pre-stress analysis is performed for each case. The value of coefficient of friction is chosen as 0.8 in the analysis.

The experimental and the numerical natural frequencies of the tire contacted by the ground are compared in Table 5, under three different inflation pressures and the constant vertical load of $1215 \mathrm{~N}$. Except the increase of the experimentally measured first natural frequency, $91.24 \mathrm{~Hz}$, for the inflation pressure of $241 \mathrm{kPa}$ in Table 5, all results are in good agreement. This high value, $91.24 \mathrm{~Hz}$, might be either a torsion vibration mode with missing first natural frequency, or due to an experimental error. The natural frequencies increase with increased inflation pressure, as occurred in the free vibration analysis.

Figure 3 shows the first six mode shapes of the tire contacted by the ground and fixed in the rim contact points. That means, mode shapes are determined at fixed contacted boundary conditions. The vertical load of $4000 \mathrm{~N}$ and the inflation pressure of $241 \mathrm{kPa}$ are used in this analysis with 0.8 friction coefficient between the tire and ground.

Table 5. The natural frequencies of the tire (175/70 R13), contacted by ground under three different inflation pressures and a constant vertical load of $1215 \mathrm{~N}$

\begin{tabular}{|c|c|c|c|c|c|c|}
\hline \hline $\begin{array}{c}\text { Inflation } \\
\text { pressures }\end{array}$ & \multicolumn{2}{|c|}{$159 \mathrm{kPa}$} & \multicolumn{2}{c|}{$200 \mathrm{kPa}$} & \multicolumn{2}{c|}{$241 \mathrm{kPa}$} \\
\hline $\begin{array}{c}\text { Natural } \\
\text { frequencies }\end{array}$ & $\begin{array}{c}\text { Numerical } \\
(\mathrm{Hz})\end{array}$ & $\begin{array}{c}\text { Experimental } \\
(\mathrm{Hz})\end{array}$ & $\begin{array}{c}\text { Numerical } \\
(\mathrm{Hz})\end{array}$ & $\begin{array}{c}\text { Experimental } \\
(\mathrm{Hz})\end{array}$ & $\begin{array}{c}\text { Numerical } \\
(\mathrm{Hz})\end{array}$ & $\begin{array}{c}\text { Experimental } \\
(\mathrm{Hz})\end{array}$ \\
\hline 1 & 65.99 & 53.06 & 70.46 & 57.1 & 74.40 & 91.24 \\
\hline 2 & 129.12 & 121.43 & 140.77 & 123.39 & 150.75 & 142.48 \\
\hline 3 & 147.07 & 152.83 & 159.85 & 155.51 & 171.42 & 171 \\
\hline 4 & 172.01 & 193.65 & 184.21 & 193.66 & 193.30 & 203.37 \\
\hline 5 & 209.72 & - & 217.67 & 237.59 & 221.96 & 244.69 \\
\hline
\end{tabular}



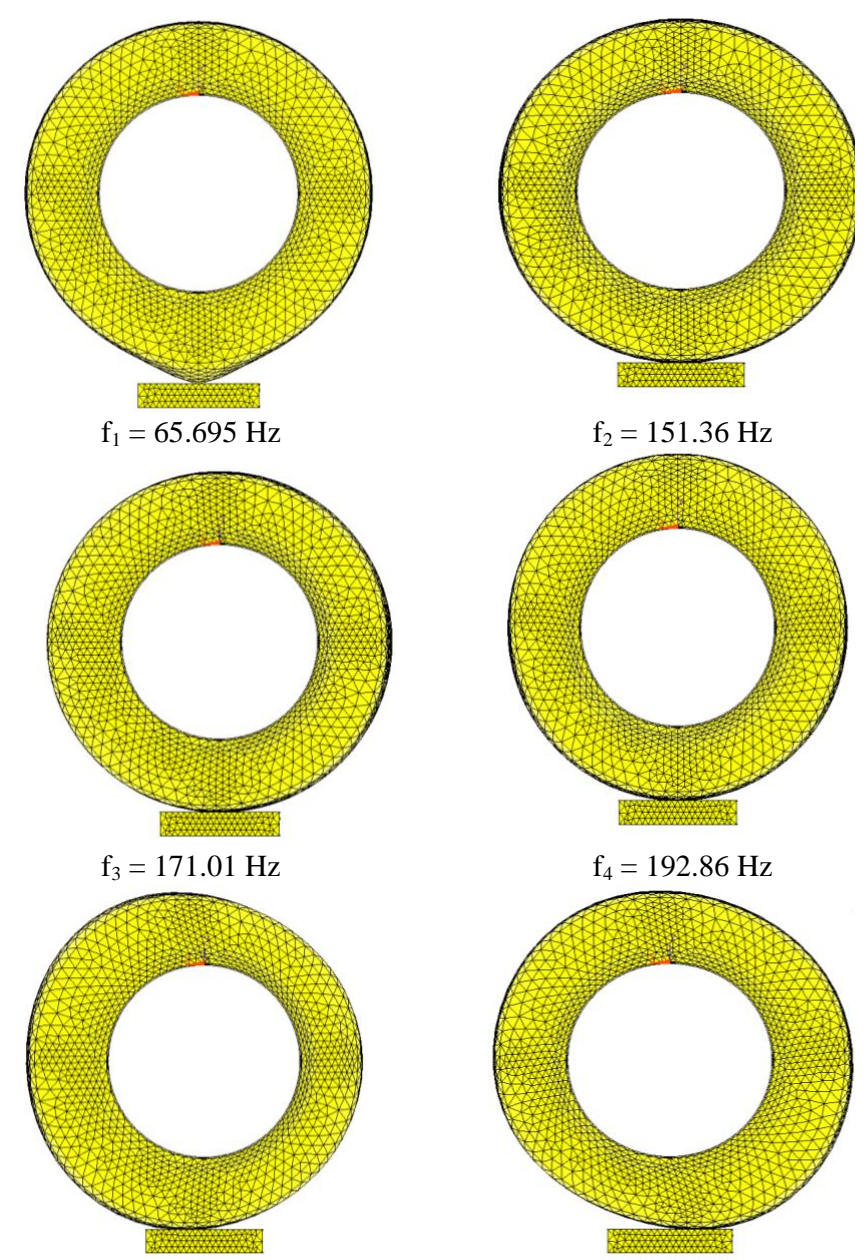

$\mathrm{f}_{5}=225.02 \mathrm{~Hz}$

$\mathrm{f}_{6}=241.22 \mathrm{~Hz}$

Fig. 3. Mode shapes of the tire vibration (175/70 R13) under the vertical load of $4000 \mathrm{~N}$, the pressure of $241 \mathrm{kPa}$ and for the friction coefficient of 0.8 .

The numerical results are shown in Table 6 and in Figs. 4-10, under four different vertical forces, three different inflation pressures and coefficients of friction. The inflation pressure is the most effective factor on the natural frequencies, which increase with increased inflation pressure up to $25 \%$ under constant vertical load and coefficient of friction. This relationship is almost perfectly linear for the all six natural frequencies, but the percentage ratios vary (Figs. 4-6). On the other hand, the effect of the coefficient of friction is different and much more complex on the all six fre- 
Table 6. The natural frequencies of the tire (175/70 R13), contacted by ground under three different inflation pressures and coefficient of friction with vertical load of $(F=) 2000 \mathrm{~N}$

\begin{tabular}{|c|c|c|c|c|c|c|c|c|c|}
\hline \hline$F=2000 \mathrm{~N}$ & \multicolumn{9}{|c|}{ Coefficients of friction } \\
\hline & \multicolumn{3}{|c|}{0.1} & \multicolumn{3}{c|}{0.4} & \multicolumn{3}{c|}{0.8} \\
\hline & \multicolumn{3}{|c|}{ Inflation pressure $(\mathrm{kPa})$} & \multicolumn{3}{c|}{ Inflation pressure $(\mathrm{kPa})$} & \multicolumn{3}{c|}{ Inflation pressure $(\mathrm{kPa})$} \\
\hline $\mathrm{f}(\mathrm{Hz})$ & 159 & 200 & 241 & 159 & 200 & 241 & 159 & 200 & 241 \\
\hline 1 & 62.657 & 67.589 & 71.973 & 62.744 & 67.452 & 71.798 & 62.943 & 67.484 & 71.603 \\
\hline 2 & 125.06 & 136.51 & 147.85 & 127.90 & 139.5 & 149.94 & 129.23 & 140.85 & 151.39 \\
\hline 3 & 147.02 & 159.87 & 171.5 & 146.96 & 159.76 & 171.39 & 146.94 & 159.7 & 171.29 \\
\hline 4 & 155.9 & 168.46 & 182.39 & 164.56 & 177.14 & 188.86 & 171.28 & 183.52 & 195.48 \\
\hline 5 & 207.5 & 214.75 & 222.71 & 209.25 & 217.19 & 222.34 & 209.74 & 217.68 & 224.55 \\
\hline 6 & 215.3 & 222.45 & 230.83 & 221.90 & 229.73 & 230.38 & 228.9 & 236.41 & 237.56 \\
\hline
\end{tabular}

quencies under different vertical load and inflation pressure conditions. Some results are calculated more than once and again the same results are observed.

The coefficient of friction is nearly not effective for the first natural frequency up to the vertical load of $3000 \mathrm{~N}$. If the coefficient of friction increases from 0.1 to 0.8 under the vertical load of $4000 \mathrm{~N}$ and inflation pressure of $159 \mathrm{kPa}$, then the first natural frequency has a maximum increase, $6.8 \%$ (Figs. 7-9). Almost, there is no change in the third natural frequency under neither different coefficient of frictions nor vertical forces. Only, the inflation pressure is effective in it. Second, fourth, fifth and sixth natural frequencies mostly increase with increased coefficient of friction in addition to inflation pressure. The fourth natural frequency has the maximum increase, $10 \%$, when either the coefficient of friction increases from 0.1 to 0.8 or the inflation pressure increases from $159 \mathrm{kPa}$ to $200 \mathrm{kPa}$ under the vertical load of 4000 N (Figs. 7-9).

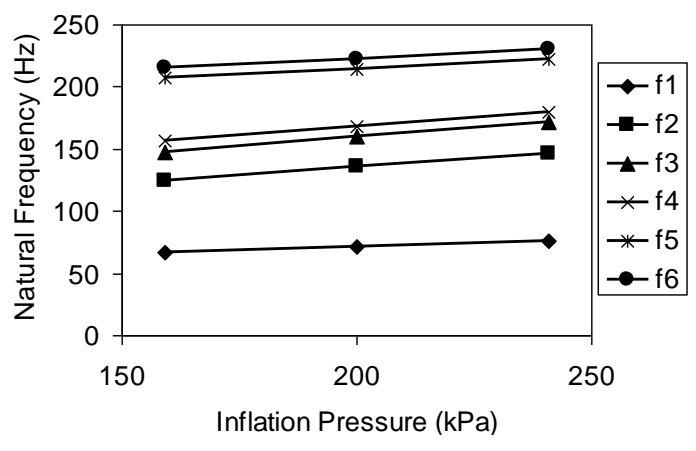

Fig. 4. The natural frequencies of the tire (175/70 R13), contacted by ground under three different inflation pressures with vertical load of $1000 \mathrm{~N}$ and the coefficient of friction of 0.1 . 


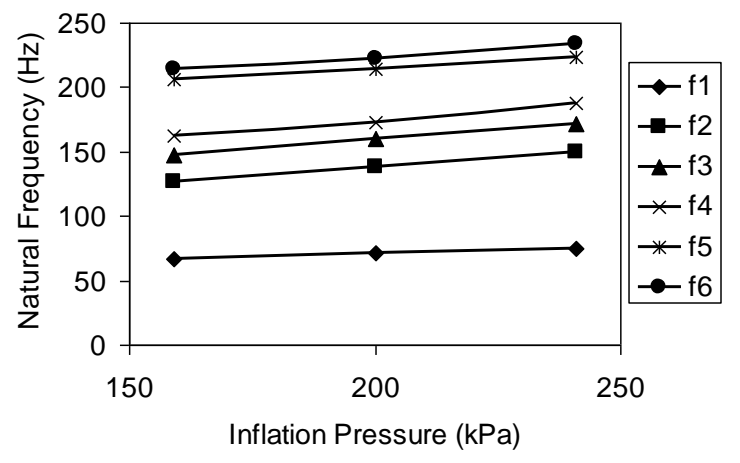

Fig. 5. The natural frequencies of the tire (175/70 R13) contacted by ground under three different inflation pressures with vertical load of $1000 \mathrm{~N}$ and the coefficient of friction of 0.4 .

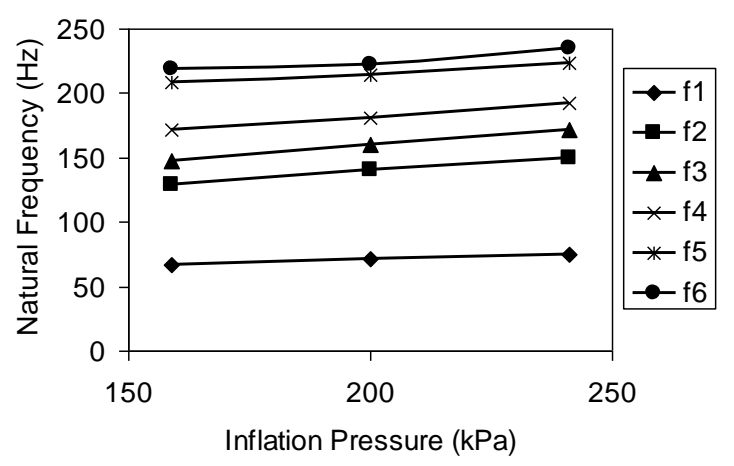

Fig. 6. The natural frequencies of the tire (175/70 R13) contacted by ground under three different inflation pressures with vertical load of $1000 \mathrm{~N}$ and the coefficient of friction of 0.8 .

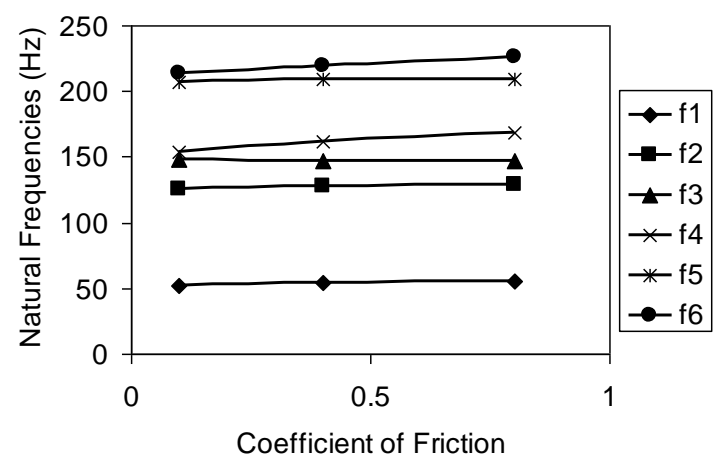

Fig. 7. The natural frequencies of the tire (175/70 R13) contacted by ground under three different coefficients of friction with vertical load of $4000 \mathrm{~N}$ and inflation pressure of $159 \mathrm{kPa}$. 


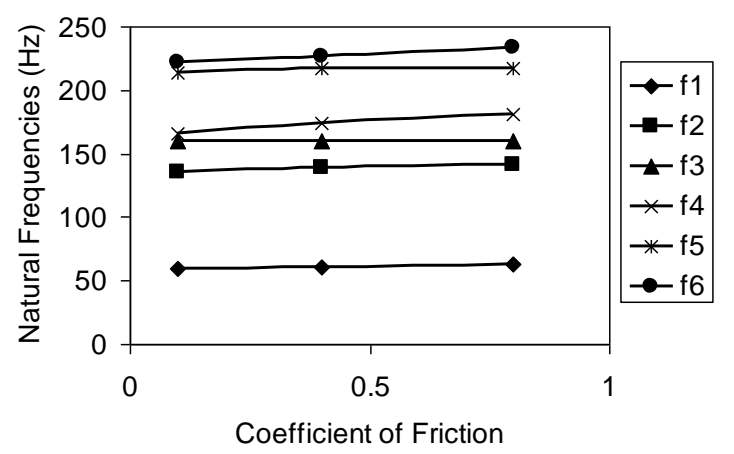

Fig. 8. The natural frequencies of the tire (175/70 R13) contacted by ground under three different coefficients of friction with vertical load of $4000 \mathrm{~N}$ and inflation pressure of $200 \mathrm{kPa}$.

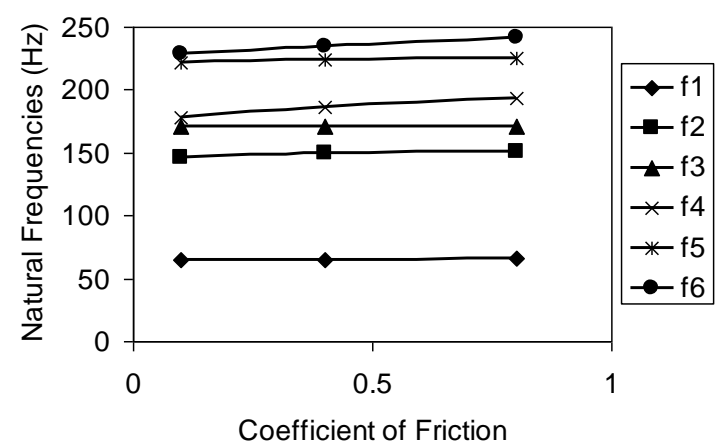

Fig. 9. The natural frequencies of the tire (175/70 R13) contacted by ground under three different coefficients of friction with vertical load of $4000 \mathrm{~N}$ and inflation pressure of $241 \mathrm{kPa}$.

The vertical load is mostly effective on the first natural frequency. It decreases with increased vertical load using the numerical model in this study. Probably the reason of it is that the contact area is taken as constant in the analysis, as Kozhevnikov [5] uses the same approach for the calculation. On the other hand, Kim et al. [7] measures only the first natural frequency and indicates that it goes higher, as the applied load to the tire increases, because increasing the mass of the tire causes a stiffer sidewall. Although the increase is higher between the vertical load of $500 \mathrm{~N}$ and $1000 \mathrm{~N}$, it is very low, less than $3 \%$, between the vertical load of $1000 \mathrm{~N}$ and $2500 \mathrm{~N}$ in their study. Findings of Guan et al. [8] are also similar for the effect of vertical load on the first five natural frequencies of the tire: the influence of changes of the vertical load on the tire natural frequencies is less up to $3000 \mathrm{~N}$. The second and third natural frequencies are nearly constant under varied vertical load. However, the fourth natural frequency has very different characteristics. It either increases or decreases up to $2 \%$ under different vertical loads when the fourth natural frequency 


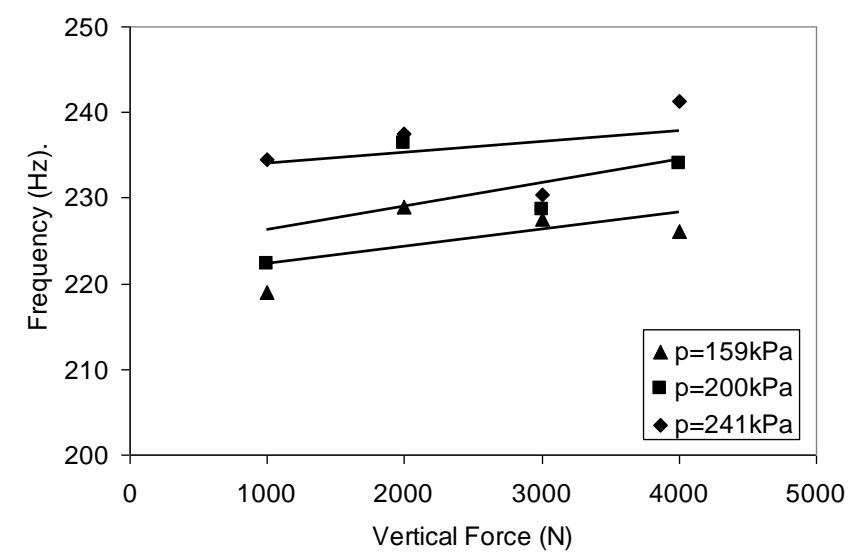

Fig. 10. The sixth natural frequency of the tire (175/70 R13) contacted by ground, under four different vertical loads with the coefficient of friction of 0.8 and inflation pressures (p) of $159 \mathrm{kPa}, 200 \mathrm{kPa}$, and $241 \mathrm{kPa}$.

of $F=1000 \mathrm{~N}$ is taking as reference value. A little increase, e.g. max $1.5 \%$ between the vertical load of $1000 \mathrm{~N}$ and $2000 \mathrm{~N}$ for the friction coefficient of 0.8 and the inflation pressure of $200 \mathrm{kPa}$, is observed on the fifth natural frequency. In addition, it is stable under the condition of 0.1 friction coefficient. Although the sixth natural frequency is nearly constant under the condition of 0.1 friction coefficient similar to the fifth one, the increase which is maximum $6.3 \%$ under the inflation pressure of $200 \mathrm{kPa}$ and coefficient of friction of 0.8 when the force is increased from $1000 \mathrm{~N}$ to $2000 \mathrm{~N}$ is seen in the other cases as shown in Fig. 10.

Examining the impact of three different factors together on the natural frequencies is quite difficult. It is easier to see the effects when some of these factors are assumed to be constant and the variables are taken one by one.

\section{CONCLUSIONS}

The natural frequencies are measured experimentally, using the damping monitoring method and modelled numerically, to describe the free vibration and vibration of the tire in ground contact. According to the results, the inflation pressure is the most effective parameter on the natural frequencies which increase with increased inflation pressure. This relationship is almost perfectly linear for the all six natural frequencies, but the percentage ratios vary. On the other hand, the effects of the coefficient of friction and the vertical load are different and much more complex on the first six natural frequencies. From the numerical solutions with the different inflation pressures, vertical loads and coefficients of friction, it is shown that these physical parameters have influences to the vibration of the tire. An efficient numerical approach 
is presented to predict the vibration frequencies of the car tire under three different parameters. It is also demonstrated experimentally, that this model is accurate and effective for computing vibrations of the tire in working conditions.

\section{REFERENCES}

[1] Kung, L. E. Radial Vibrations of Pneumatic Radial Tires, SAE Technical Paper Series, 1990, 5p, 900759

[2] JiA, L., Y. XU, J. Zhang. Free Vibration Analysis of Radial Pneumatic Tires Using Bezier Functions. J. Sound Vib., 285 (2005), 887-903.

[3] WAKI, Y., B. R. MACE, M. J. BRENnAN. Free and Forced Vibrations of a Tyre Using a Wave/Finite Element Approach. J. Sound Vib., 323 (2009), 737-756.

[4] Soedel, W., M. G. Prasad. Calculation of Natural Frequencies and Modes of Tires in Road Contact Utilizing Eigen Values of the Axi-symmetric Non-contacting Tire. $J$. Sound Vib., 70 (1980), No. 4, 573-584.

[5] Kozhevnikov, I. F. The Vibrations of a Free and Loaded Tyre. J. Appl. Math. Mech., 70 (2006), 223-228.

[6] Huang, S. C. The Vibration of Rolling Tyres in Ground Contact. Int. J. of Vehicle Des., 13 (1992), No. 1, 78-95.

[7] KIM, B. S., C. H. CHI, T. K. LEE. A Study on Radial Directional Natural Frequency and Damping Ratio in a Vehicle Tire. Appl. Acoust., 68 (2007), 538-556.

[8] Guan, Y., G. Cheng, G. Zhao, H. Zhang. Investigation of the Vibration Characteristics of Radial Tires using Experimental and Numerical Techniques. J. Reinf. Plast. Comp., 30 (2011), No. 24, 2035-2050.

[9] Geng, Z., A. A. Popov, D. J. Cole. Measurement, Identification and Modelling of Damping in Pneumatic Tyres. Int. J. Mech. Sci., 49 (2007), 1077-1094.

[10] Chetpattananondh, K., C. Dechwayukul, W. Thongruang. An Applied Laser Shade Vibration Measurement Technique for Rotating Imbalance for Quality Testing of Solid Tires. Measurement, 41 (2008), 922-933.

[11] Kim, Y. J., J. S. Bolton. Effects of Rotation on the Dynamics of a Circular Cylindrical Shell with Application to Tire Vibration. J. Sound Vib., 275 (2004), 605-621.

[12] Lopez, I., R. E. A. Blom, N. B. Roozen, H. NiJneiJer. Modelling Vibrations on Deformed Rolling Tyres- a Modal Approach. J. Sound Vib., 307 (2007), 481-494.

[13] LI, Y., S. Zuo, L. LeI, X. YANG, X. Wu. Characteristics' Analysis of Lateral Vibration of Tire Tread. J. Vib. Control., 17 (2011), No. 14, 2095-2102.

[14] Brinkmeier, M., U. Nackenhorst. Simulation and Measurements of Rolling Tire Dynamics. PAMM Proc. Appl. Math. Mech., 6 (2006), 293-294.

[15] Johnson, T. J., D. E. AdAms. Composite Indices Applied to Vibration Data in Rolling Tires to Detect Bead Area Damage. Mech. Syst. Signal Pr., 21 (2007), 21612184. 
[16] Rustighi, E., S. J. Elliott, S. Finnveden, K. Gulyas, T. Mocsal, M. Danti. Linear Stochastic Evaluation of Tyre Vibration Due to Tyre/Road Excitation. J. Sound Vib., 310 (2008), 1112-1127.

[17] Fujikawa, T., H. Koike, Y. Osheino, H. Tachibana. Definition of Road Roughness Parameters for Tire Vibration Noise Control. Appl. Acoust., 66 (2005), 501-512.

[18] LEE, T. K., B. S. KIM. Vibration Analysis of Automobile Tire Due to Bump Impact. Appl. Acoust., 69 (2008), 473-478.

[19] Colakoglu, M. Effect of Temperature on Frequency and Damping Properties of Polymer Matrix Composites. Adv. Compos. Mater., 17 (2008), 111-124.

[20] SoYKASAP, O. Micromechanical Models for Bending Behaviour of Woven Composites. J. Spacecraft Rockets., 43 (2006), 1093-1100.

[21] Colakoglu, M., O. Soykasap, T. OzeK. Experimental and Numerical Investigations on the Ballistic Performance of Polymer Matrix Composites used in Armor Design. Appl. Compos. Mater., 14 (2007), No. 1, 47-58. 